\title{
Leak compensation in positive pressure ventilators: a lung model study
}

\author{
S. Mehta*, F.D. McCool ${ }^{\#}$, N.S. Hill
}

Leak compensation in positive pressure ventilators: a lung model study. S. Mehta, D. McCool, N. Hill. (C)ERS Journals Ltd 2001.

ABSTRACT: Leak compensating abilities of six different positive pressure ventilators commonly used to deliver noninvasive positive pressure ventilation, including the bilevel positive airway pressure (BiPAP) S/T-D and Quantum (Respironics Inc, Murrysville, PA, USA), 335 and $O^{\prime}$ NYX (Mallinckrodt Inc, St Louis, MO, USA), PLV 102 (Respironics), and Siemens Servo 900C (Siemens Inc, Danvers, MA, USA).

Using a test lung model, compensatory capabilities of the ventilators were tested for smaller and larger leaks using the assist/control or timed modes. Back-up rate was $20 \cdot \mathrm{min}^{-1}$, inspiratory pressure was $18 \mathrm{cmH}_{2} \mathrm{O}$, and expiratory pressure was $5 \mathrm{cmH}_{2} \mathrm{O}$.

It was found that even in the absence of air leaking, delivered tidal volume differed substantially between the ventilators during use of pressure-targeted modes, depending on inspiratory flows, inaccuracies in set versus delivered pressures, and inspiratory duration. Also during pressure-targeted ventilation, increasing the $t \mathrm{I} / t$ tot up to, but not beyond, 0.5 improved compensation by lengthening inspiratory duration, whereas use of a sensitive flow trigger setting tended to cause autocycling during leaking, interfering with compensation. Leaking interfered with cycling of the BiPAP S/T, inverting the I: $E$ ratio, shortening expiratory time, and reducing delivered tidal volume. Volume-targeted modes achieved limited compensation for small air leaks, but compensated poorly for large leaks.

To conclude, leak-compensating capabilities differ markedly between ventilators but pressure-targeted ventilators are preferred for noninvasive positive pressure ventilation in patients with substantial air leaking. Adequate inspiratory flows and durations should be used, triggering sensitivity should be adjusted to prevent autocycling, and a mechanism should be available to limit inspiratory time and avoid I:E ratio inversion.

Eur Respir J 2001; 17: 259-267.
*Mt. Sinai Hospital, University of Toronto, Toronto, Canada, ${ }^{\#}$ Memorial Hospital of Rhode Island and Rhode Island Hospital and Brown University School of Medicine, Providence, RI, USA.

Correspondence: N.S. Hill, Division of Pulmonary, Sleep, and Critical Care Medicine, Rhode Island Hospital, 593 Eddy Street, Providence, RI 02903, USA.

Fax: 14014446665

Keywords: Mask ventilation mechanical ventilators noninvasive ventilation portable ventilators

Received: September 301999 Accepted after revision August 212000
Noninvasive positive pressure ventilation (NPPV) is widely used to assist breathing in both acute and chronic forms of respiratory failure $[1,2]$. In contrast to invasive ventilation, NPPV uses an open circuit design that is inherently leaky. Although ventilation can often be assisted even in the presence of sizeable leaks [3], different ventilators and ventilator modes may be more or less capable of compensating for air leaks. This compensatory capability may be important in optimizing the success of NPPV, but few studies have examined the effectiveness of different ventilators in delivering ventilation in the face of air leaks.

Air leaks during NPPV consist of either mask leaks between the skin and mask, mouth leaks with nasal ventilation, or nose leaks with mouthpiece ventilation. Some air may also escape via the oesophagus, but because of the relatively high impedance posed by the lower oesophageal sphincter [4], this route is likely to be minor in comparison to the others. Studies on patients using nocturnal volume- or pressure-limited ventilation have found that air leaks occur during most of sleep [3, 5]. These studies show that ventilation and oxygenation are adequately supported in most patients despite the presence of leaks, but that large leaks may interfere with ventilator cycling, compromise minute ventilation, and cause sleep fragmentation due to leak-associated arousals $[3,5]$.

Simple bedside interventions may alleviate air leaking. Mask leaks can be reduced by ensuring proper mask fit and by using optimal headstrap tension. The temptation to merely tighten the straps to reduce air leaking must be resisted, because this may reduce patient comfort and tolerance of NPPV, and promote the development of nasal bridge ulcers [6]. Air leaking through the mouth that occurs during nasal ventilation can be reduced by encouraging patients to keep their mouths closed, using chin straps, or switching to a mouthpiece or an oronasal mask [6]. However, air leaks often persist despite these interventions.

For these reasons, ventilators that are designed to compensate for air leaks are desirable for noninvasive ventilation. Using a lung model testing system, the leak compensating abilities of six positive pressure ventilators commonly used to administer NPPV, including pressure-targeted and volume-targeted devices were evaluated and compared. It was hypothesized that 
ventilator characteristics such as mode of ventilation, peak inspiratory flow capabilities, triggering sensitivities, and criteria for termination of inspiration as well as lung characteristics such as resistance and compliance, would determine the effectiveness of leak compensation.

\section{Methods}

\section{Description of the ventilators}

The leak compensation characteristics of commercially available positive-pressure ventilators, five portable and one "critical care", selected to represent the range of ventilators commonly used to deliver NPPV were evaluated. These included three pressure-limited "bilevel positive airway pressure" (BiPAP) type ventilators, the BiPAP S/T-D and Quantum Pressure Support Ventilator (Respironics, Murrysville, PA, USA), and the Nellcor Puritan Bennett 335 (Mallinckrodt, St. Louis, MO, USA). These are blowerbased flow generators capable of delivering continuous positive airway pressure (CPAP) or cycling between inspiratory and expiratory positive airway pressure (IPAP and EPAP, respectively). Other ventilators selected because they are often used for NPPV included the PLV 102 (Respironics), a piston-driven portable volume-targeted ventilator, the blower-driven $\mathrm{O}^{\prime} \mathrm{NYX}$ (Mallinckrodt), a ventilator commonly used in Europe but not yet available in North America, and the Siemens Servo 900C (Siemens Inc, Danvers, MA, USA), a critical care ventilator used widely throughout the world. The latter two ventilators deliver either pressure- or volume-targeted breaths.

All ventilators were tested in controlled modes using a back-up rate. The BiPAP ventilator was evaluated in both the spontaneous/timed (S/T) and timed (T) modes, and the Quantum, 335, and PLV 102 were evaluated in the assist/control mode. For the O'NYX and Siemens ventilators, both pressure-targeted (assist controlled pressure ventilation (ACPV) and pressure control ventilation (PCV), respectively) and volume-targeted (assist control ventilation, ACV) modes were evaluated.
Important differences between the ventilators are listed in table 1. These include differences in inspiratory termination (cycling) criteria between the ventilators. The Quantum 335 and Siemens (for both modes) use a timer set by the I:E ratio when inspirations are triggered by the timed back-up rate, whereas BiPAP in the $\mathrm{S} / \mathrm{T}$ mode cycles in response to a decrease in inspiratory flow [7]. For this reason, the timed (T) mode on the BiPAP that cycles into expiration based on a preset timer was also tested. Ventilator tubing used was that recommended by the manufacturer. The Whisper Swivel ${ }^{\mathrm{TM}}$, a fixed exhalation valve, was used with the BiPAP ventilators. For the $\mathrm{O}^{\prime}$ NYX, Siemens and PLV 102 , separate inspiratory and expiratory circuits and exhalation valves were used as supplied by the manufacturer.

\section{Leak testing system}

Each ventilator was tested using a double compartment lung model (Dual Adult Training Test Lung Model 1600, Michigan Instruments, Grand Rapids, MI, USA) connected to a $7 \mathrm{~mm}$ internal diameter (ID) endotracheal tube. The lung model was placed inside a body plethysmograph that measured volume displacement of the lung model by means of an externally connected wedge spirometer (fig. 1). Lung model compliances of $0.1,0.06$, and $0.03 \mathrm{~L} \cdot \mathrm{cm}^{-1}$ were used. Resistance could be altered by the insertion of one of two nonlinear resistors with a fixed orifice ( $\operatorname{Rp} 5$ or $\mathrm{Rp} 20$; Michigan Instruments) between the endotracheal tube and the ventilator circuit. At a flow rate of $60 \mathrm{~L} \cdot \mathrm{min}^{-1}$, the resistance of the Rp 5 and $\mathrm{Rp} 20$ was $2.7 \mathrm{cmH}_{2} \mathrm{O} \cdot \mathrm{L} \cdot \mathrm{s}^{-1}$ and $17.6 \mathrm{cmH}_{2} \mathrm{O} \cdot \mathrm{L} \cdot \mathrm{s}^{-1}$, respectively.

Ventilators were tested in the absence of leak and in the presence of a smaller or larger leak. A sidearm extended from the ventilator circuit permitted control of the amount of leak (fig. 1). Controlled leaks were created by inserting resistors into the sidearm. The resistors $\left(1.0\right.$ and $0.2 \mathrm{cmH}_{2} \mathrm{O} \cdot \mathrm{L} \cdot \mathrm{s}^{-1}$, respectively, at flow rates of $60 \mathrm{~L} \cdot \mathrm{s}^{-1}$ ) were selected to allow leakage of $1 / 4$ (small leak) and 1/2 (large leak) of the delivered tidal volume $(V \mathrm{~T})$ when the BiPAP in the T mode was set

Table 1.-Abbreviations and characteristics of ventilators evaluated

\begin{tabular}{|c|c|c|c|c|c|c|c|}
\hline Ventilator & Abbreviation & $\begin{array}{l}\text { IPAP range, } \\
\mathrm{cmH}_{2} \mathrm{O}\end{array}$ & $\begin{array}{l}\text { Adjustable trigger/ } \\
\text { cycling sensitivities }\end{array}$ & $\begin{array}{l}\text { Ramp } \\
\text { function }\end{array}$ & $\begin{array}{l}\text { Digital } \\
\text { display }\end{array}$ & $\begin{array}{l}\text { Remote } \\
\text { control }\end{array}$ & Alarms \\
\hline BiPAP S/T-D & $\begin{array}{l}\text { BiPAP } S / T \\
\text { or } T\end{array}$ & $4-20$ & $\mathrm{No} / \mathrm{No}$ & No & $\mathrm{No}^{\#}$ & $\mathrm{No}^{\#}$ & $\begin{array}{l}\text { No; high/low pressure } \\
\text { alarms can be added }\end{array}$ \\
\hline MNPB 335 & 335 & $3-35$ & Yes/Yes & Yes & Yes & Yes & Disconnect, leak \\
\hline $\mathrm{O}^{\prime} \mathrm{NYX}$ & $\mathrm{O}^{\prime} \mathrm{NYX}$ & $3-40^{\top}$ & Yes/Yes & No & Yes & No & $\begin{array}{l}\text { Disconnect, } V \mathrm{~T} \text { out } \\
\text { of set limits }\end{array}$ \\
\hline Quantum PSV & Quantum & $2-30$ & $\mathrm{No} / \mathrm{N}$ & $\mathrm{Ye}$ & $\mathrm{Ye}$ & Yes & Disconnect, pressure \\
\hline PLV 102* & PLV & $0-100$ & Yes/No & No & Yes & No & $\begin{array}{l}\text { Multiple, inclusing high/low } \\
\text { pressure, and disconnect }\end{array}$ \\
\hline Siemens $900 \mathrm{C}$ & Siemens & $0-100^{+}$ & Yes/No & No & Yes & No & $\begin{array}{l}\text { High pressure, high/low } \\
\text { minute ventilation }\end{array}$ \\
\hline
\end{tabular}

IPAP: inspiratory positive airway pressure; BiPAP: bi-level positive airway pressure; S/T spontaneous/timed; T: timed; MNPB: Mallinkrodt Nellcor Puritan Bennet; $V \mathrm{~T}$ : tidal volume; PSV: pressure support ventilator; *: a volume-targeted ventilator; ${ }^{\#}$ : available on S/T-D with remote control; ${ }^{\uparrow}$ : assist controlled pressure ventilation is the pressure-targeted mode, and the $\mathrm{O}^{\prime} \mathrm{NYX}$ also has a volume-targeted mode; ${ }^{+}$: pressure level above positive end-expiratory pressure (PEEP); ${ }^{\S}$ : alarm not active during spontaneous pressure support and PEEP mode. For ventilator manufacturers see text. 


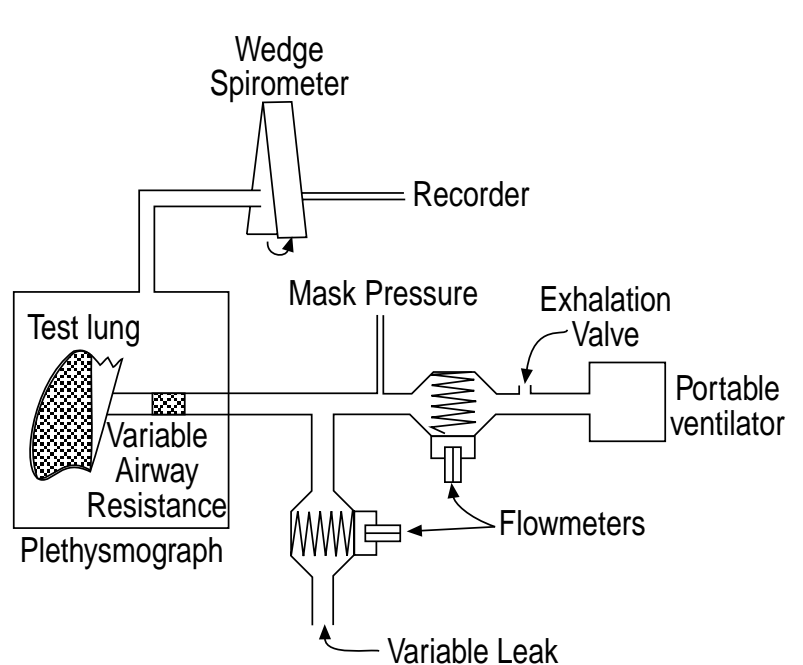

Fig. 1. - Schematic of test lung set-up. The circuit of the ventilator device being evaluated was connected to a double compartment Michigan test lung placed inside a body plethysmograph, that measured volume displacement of the lung model by means of an externally connected wedge spirometer. Airway resistance was altered by inserting a parabolic resistor proximal to the endotracheal tube. The sidearm extending from the ventilator circuit was partially occluded with different sized resistors to simulate small or large leaks. Ventilator and leak flows were measured using flowmeters as shown in the diagram. Airway pressure was measured proximal to the leak.

at IPAP/EPAP settings that delivered a $V \mathrm{~T}$ of $1 \mathrm{~L}$ in the absence of leak. The leak flow varied widely depending on the ventilator settings, but ranged from $15-30 \mathrm{~L} \cdot \mathrm{min}^{-1}$ for the small leak and $30-120 \mathrm{~L} \cdot \mathrm{min}^{-1}$ for the large leak. These were selected to span above and below the range previously reported in sleeping patients using the BiPAP S/T $\left(24-38 \mathrm{~L} \cdot \mathrm{min}^{-1}\right)$ [3]. As the amount of leak was varied, airway pressure, inspiratory and leak flows and $V \mathrm{~T}$ were measured using inline manometers and pneumotachographs (Fleisch No. 2) and recorded using a Gould 3800 strip chart recorder (Gould, Cleveland, $\mathrm{OH}, \mathrm{USA}$ ).

\section{Experimental settings}

For baseline comparisons, respiratory frequency was set at 20 breaths $\cdot \mathrm{min}^{-1}$ in all of the experiments to reflect commonly recommended breathing rates for noninvasive ventilation $[8,9]$. IPAP/EPAP settings were 18 and $5 \mathrm{cmH}_{2} \mathrm{O}$ respectively for the BiPAP (in both $\mathrm{T}$ and S/T modes), 335, and Quantum ventilators. Inspiratory and expiratory sensitivity settings on the 335 were 2 and 3 , respectively, with 1 being the most and 5 the least sensitive settings [7]. In order to match the IPAP/EPAP settings, the $\mathrm{O}^{\prime} \mathrm{NYX}$ in the ACPV mode was at a pressure support of $13 \mathrm{cmH}_{2} \mathrm{O}$ and a PEEP of $5 \mathrm{cmH}_{2} \mathrm{O}$ and the inspiratory trigger was set at $1.5 \mathrm{cmH}_{2} \mathrm{O}$ ( 0 being the most and 3 the least sensitive settings). Inspiratory time/total breath time ( $t \mathrm{I} / t$ tot $)$ was set at 0.33 , and test lung compliance at $0.1 \mathrm{~L} \cdot \mathrm{cmH}_{2} \mathrm{O}$.

To test the effect of differences in inspiratory duration on delivered $V \mathrm{~T}, t \mathrm{I} / \mathrm{t}$ tot was varied $(0.25,0.33$ or 0.50) for the BiPAP and PLV. The BiPAP T was additionally tested at a $t \mathrm{I} / t$ tot of 0.66 to determine the effect of inverted I:E ratios on delivered $V \mathrm{~T}$. The influence of inspiratory trigger sensitivity was tested by using the $\mathrm{O}^{\prime} \mathrm{NYX}$ at inspiratory sensitivities of $0.5,1.5$ and $3.0 \mathrm{cmH}_{2} \mathrm{O}$. The effect of changes in respiratory system compliance and resistance on tidal volumes delivered in the presence of leak were evaluated using the 335 at test lung compliances of $0.1,0.06$ and $0.03 \mathrm{~L} \cdot \mathrm{cmH}_{2} \mathrm{O}$. With test lung compliance set at $0.1 \mathrm{~L} \cdot \mathrm{cmH}_{2} \mathrm{O}$, each of 3 resistance conditions (no resistor, $\mathrm{Rp} 5$ or $\mathrm{Rp} 20$ ) was also tested. The effect of varying leak on $V \mathrm{~T}$ delivered by volume-targeted ventilation was assessed using the PLV 102, O'NYX and Siemens at four different tidal volume settings, with test lung compliance set at $0.1 \mathrm{~L} \cdot \mathrm{cmH}_{2} \mathrm{O}$ and $t \mathrm{I} / t$ tot at 0.33 .

\section{Statistical analysis}

Six breaths were analysed and averaged for each experimental setting. All values are reported as mean $\pm \mathrm{SD}$. Repeated measures analysis of variance was used to compare mean values for each ventilator at different settings, and two way analysis of variance was used to compare mean values between different ventilators. When significant differences were detected, post hoc analysis was performed using Tukey's exact test. Very little variability occurred between breaths, so SD bars are not shown in the figures to improve clarity of presentation.

\section{Results}

\section{Leak compensation in pressure-targeted ventilators}

During pressure-targeted ventilation, delivered $V \mathrm{~T}$ differed substantially between ventilators despite equal inspiratory and expiratory pressure settings (18 and $5 \mathrm{cmH}_{2} 0$, respectively), even in the absence of leak (fig. 2a). These differences were related to variances in inspiratory flow rates, actual pressures delivered, and inspiratory duration (as determined by $t \mathrm{I} / t$ tot) (table 2 ). For example, the $400-\mathrm{mL}$ greater $V \mathrm{~T}$ delivered by the BiPAP in the S/T mode as compared to the T mode was related to a greater $t \mathrm{I} / t$ tot in the $\mathrm{S} / \mathrm{T}$ mode, allowing more time for lung inflation. In contrast, the three ventilators using volume-targeted modes consistently delivered the selected volume of $1 \mathrm{~L}$, as would be anticipated.

With all of the ventilators, when a leak was introduced into the system, airway pressure decreased (table 2) and delivered $V \mathrm{~T}$ was significantly reduced (fig. 2b). When expressed as $\%$ of $V \mathrm{~T}$ delivered in the absence of leak, $V \mathrm{~T}$ during a small leak was best maintained by the pressure-targeted modes, particularly the $\mathrm{O}^{\prime} \mathrm{NYX}$ and Siemens ventilators. The BiPAP in the $\mathrm{S} / \mathrm{T}$ mode compensated less effectively because of excessive prolongation of the inspiratory duration and, as a group, the volume-targeted modes compensated far less effectively than the pressure-targeted modes (fig. 2b). In the presence of a large leak, the 

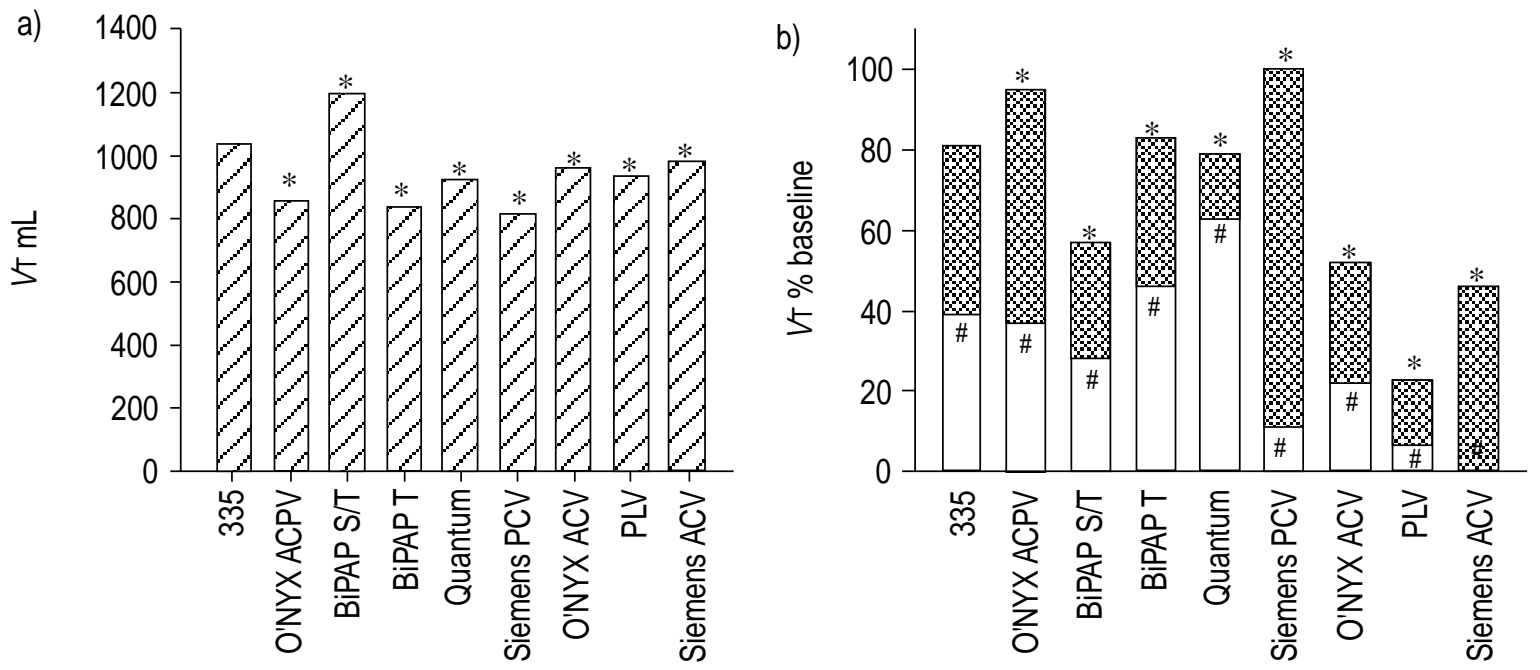

Fig. 2. - Tidal volume $(V \mathrm{~T})$ delivered by the ventilators in a) the absence of leak and b) during leak, the latter expressed as a percentage of the $V_{\mathrm{T}}$ delivered in the absence of leak. For the pressure-limited modes inspiratory positive airway pressure/expiratory positive airway pressure (IPAP/EPAP) settings were 18 and $5 \mathrm{cmH}_{2} \mathrm{O}$, respectively, and for the volume-limited modes, VT was set at $1 \mathrm{~L}$. For all conditions, inspiratory time/total time $t \mathrm{I} / \mathrm{t}$ tot was 0.33 , and test lung compliance was $0.1 \mathrm{~L} \cdot \mathrm{cm}^{-1} \mathrm{H}_{2} \mathrm{O}$. The $\mathrm{O}^{\prime} \mathrm{NYX}$ was evaluated in the assist controlled pressure ventilation (ACPV) and assist controlled ventilation (ACV) modes with the inspiratory trigger set at $1.5 \mathrm{cmH}_{2} \mathrm{O}$. Inspiratory and expiratory sensitivity settings on the 335 were 2 and 3 respectively. The Siemens was tested in the pressure control ventilation (PCV) and ACV modes with inspiratory trigger sensitivity set at $1 \mathrm{cmH}_{2} \mathrm{O} . *: \mathrm{p}<0.01$ compared to values for 335 ; $\#: \mathrm{p}<0.01$ compared to small leak. $\square$ : large leak; small leak.

Quantum best maintained delivered $V \mathrm{~T}$, which was approximately $65 \%$ of the baseline. Once again, the pressure-targeted modes compensated much better than the volume-targeted modes, with the exception of the Siemens PCV (fig. 2b), which failed to sustain high inspiratory flow rates throughout the inspiratory duration (fig. 3).

Surprisingly, leak-compensation between the volume-targeted modes differed considerably, with the $\mathrm{O}^{\prime} \mathrm{NYX}$ in the ACV mode performing best by virtue of its ability to increase inspiratory flow rate (table 2). As would be expected with most volumetargeted ventilators, inspiratory flow rates did not change with the PLV, accounting for its poor leak compensating abilities. With the Siemens in the ACV mode, inspiratory flow rate increased slightly in the face of a large leak, but then decreased abruptly, similar to the response with the PCV mode, resulting in no measurable delivered $V_{\mathrm{T}}$ (table 2, fig. 3).

\section{Effect of set inspiratory timeltotal breath time on delivered tidal volume}

Among the "bilevel" devices that permit setting of $t \mathrm{I} /$ $t$ tot, delivered $V \mathrm{~T}$ increased as $t \mathrm{I} / t$ tot was raised from 0.25 , to 0.33 and 0.5 , both with small and large leaks (fig. 3). At each setting, the Quantum preserved leak $V$ T better than the 335 or BiPAP T, related to a longer inspiratory duration (table 2). During air leaking, the BiPAP in the S/T mode delivered a lower $V$ T (fig. 4). This was related to the fact that in the $\mathrm{S} / \mathrm{T}$ mode, the $\%$ IPAP control on the BiPAP is inoperative and does not permit adjustments of $t \mathrm{I} / t$ tot. Inspiration is

Table 2. - Peak inspiratory flows, peak airway pressure and inspiratory to total cycle ratio during leak

\begin{tabular}{|c|c|c|c|c|c|c|c|c|c|}
\hline \multirow{2}{*}{ Ventilator } & \multicolumn{3}{|c|}{ No leak } & \multicolumn{3}{|c|}{ Small leak } & \multicolumn{3}{|c|}{ Large leak } \\
\hline & Flow $^{\#} L \cdot S^{-1}$ & $P$ aw $\mathrm{cmH}_{2} \mathrm{O}$ & $t \mathrm{I} / t$ tot & Flow $\mathrm{L} \cdot \mathrm{s}^{-1}$ & $P$ aw $\mathrm{cmH}_{2} \mathrm{O}$ & $\overline{t \mathrm{I} / t \text { tot }}$ & Flow $L \cdot \mathrm{s}^{-1}$ & $P$ aw $\mathrm{cmH}_{2} \mathrm{O}$ & $t \mathrm{I} /$ tot \\
\hline BiPAP T & $1.0 \pm 0.09$ & $18 / 5$ & 0.30 & $2.1 \pm 0.1$ & $13 / 5$ & 0.30 & $2.4 \pm 0.1$ & $10 / 5$ & 0.30 \\
\hline BiPAP S/T & $1.3 \pm 0.09$ & $19 / 6$ & 0.43 & $2.1 \pm 0.09$ & $16 / 6$ & 0.70 & $2.5 \pm 0.1$ & $12 / 6$ & 0.79 \\
\hline MNPB 335 & $1.3 \pm 0.09$ & $20 / 5$ & 0.33 & $2.5 \pm 0.1$ & $16 / 6$ & 0.50 & $3.0 \pm 0.1$ & $12 / 6$ & 0.33 \\
\hline Quantum & $1.2 \pm 0.09$ & $18 / 5$ & 0.33 & $2.5 \pm 0.1$ & $15 / 4$ & 0.33 & $3.0 \pm 0.1$ & $12 / 4$ & 0.46 \\
\hline $\mathrm{O}^{\prime} \mathrm{NYX}$ ACPV & $1.1 \pm 0.02$ & $18 / 7$ & 0.33 & $2.1 \pm 0.04$ & $17 / 6$ & 0.33 & $3.4 \pm 0.05$ & $17 / 6$ & 0.88 \\
\hline Siemens PCV & $1.3 \pm 0.1$ & $16 / 5$ & 0.35 & $1.7 \pm 0.1$ & $16 / 2$ & 0.35 & $2.4 \pm 0.1$ & $15 / 0$ & 0.35 \\
\hline $\mathrm{O}^{\prime} \mathrm{NYX} \mathrm{ACV}$ & $0.8 \pm 0.1$ & $15 / 0$ & 0.25 & $1.0 \pm 0.1$ & $8 / 0$ & 0.38 & $1.8 \pm 0.1$ & $4 / 0$ & 0.47 \\
\hline PLV 102 & $1.5 \pm 0.0$ & $20 / 0$ & 0.33 & $1.5 \pm 0.0$ & $6 / 0$ & 0.33 & $1.5 \pm 0.0$ & $4 / 0$ & 0.33 \\
\hline Siemens ACV & $0.75 \pm 0.1$ & $20 / 0$ & 0.35 & $0.75 \pm 0.1$ & $10 / 0$ & 0.35 & $1.0 \pm 0.1$ & $4 / 0$ & 0.35 \\
\hline
\end{tabular}

Data are presented as means \pm SD. $P$ aw: Peak airway pressure, presented as inspiratory positive airway pressure/expiratory positive airway pressure; $t \mathrm{I} / t$ tot: ratio of inspiratory time to total respiratory cycle time; BiPAP: bilevel positive airway pressure; MNPB: Mallinkrodt Nellcor Puritan Bennett; ACPV: assist control pressure ventilation; PCV pressure control ventilation; ACV: assist controlled ventilation; ${ }^{\#}$ : peak inspiratory flow; ${ }^{\text {: }}$ trigger setting was $1.5 \mathrm{cmH}_{2} \mathrm{O}$. 


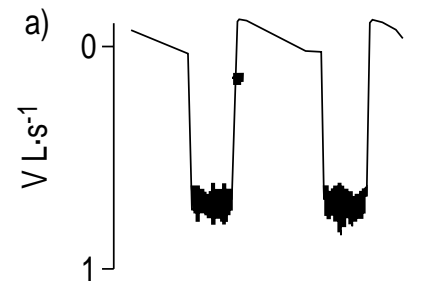

b)
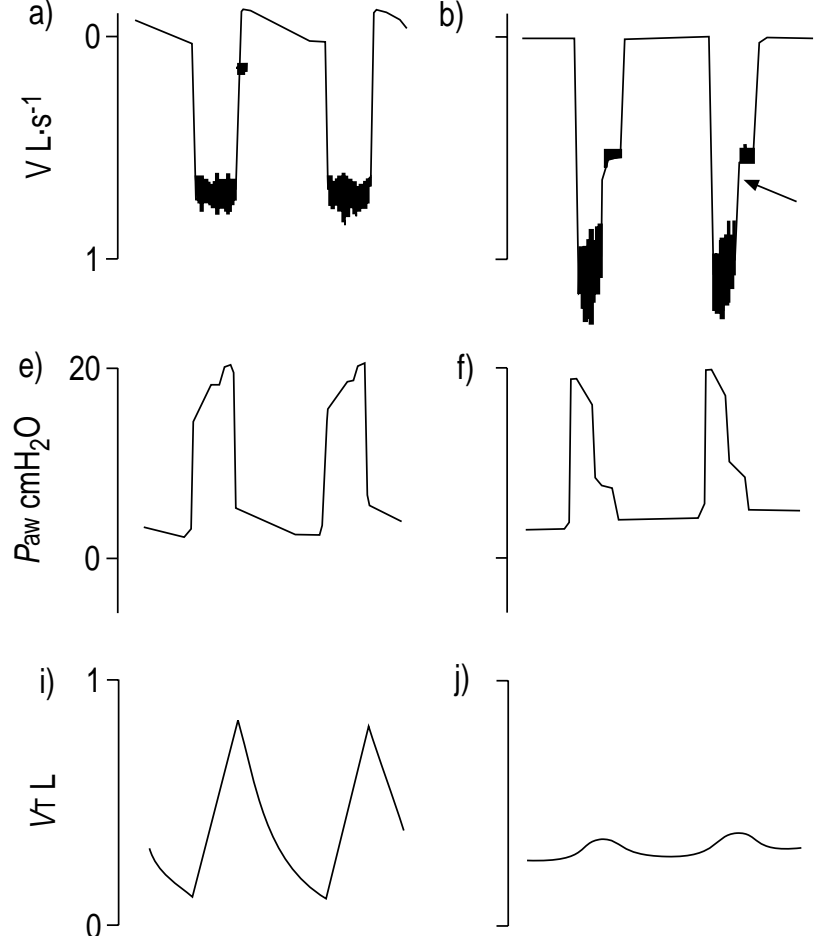

f)

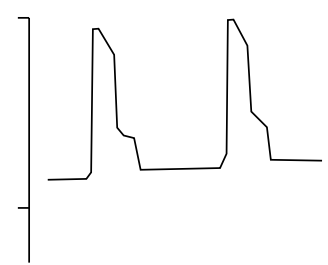

j)

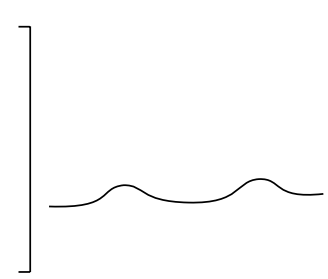

c)

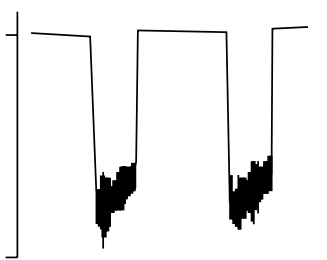

g)

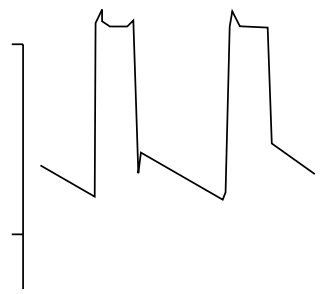

k)

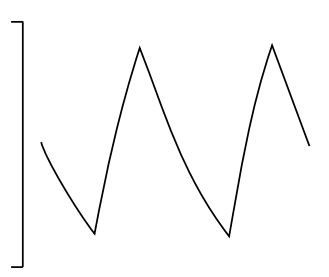

d)

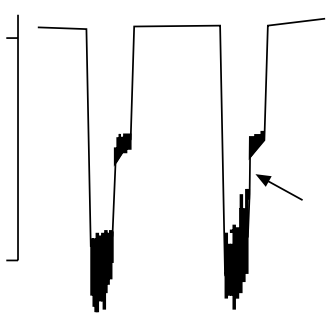

h)
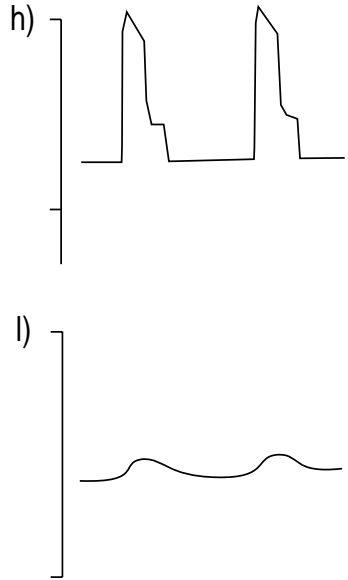

Fig. 3. - Illustration of the effect on delivered tidal volume $\left(V_{\mathrm{T}}\right)$ of failure to sustain high inspiratory flow rate by the Siemens $900 \mathrm{C}$ ventilator in the face of a large leak. Figures a, c, e, g, i, k show sustained inspiratory flow rate and adequate tidal volume delivery with a small leak in volume control (assist control ventilation; ACV) mode (a, e, i) and pressure control (pressure control ventilation; PCV) mode $(\mathrm{c}, \mathrm{g}, \mathrm{k})$ with $V_{\mathrm{T}}$ setting $1.5 \mathrm{~L}$ and inspiratory: expiratory 1:2. With a large leak in either the ACV (b, f, j) or PCV (d, h, 1) modes, inspiratory flow rate drops during the middle of inspiration (indicated by arrow), and delivered $V_{\mathrm{T}}$ is negligible.

terminated by a decrease in inspiratory flow up to a maximum duration of $3 \mathrm{~s}$; therefore, $t \mathrm{t} / t$ tot increases during leak because inspiratory flow fails to drop sufficiently to cycle the ventilator. $t \mathrm{I} / t$ tot averaged 0.47 in the absence of leak, and increased to 0.8 with a small or large leak. To illustrate this effect of excessive prolongation of $t \mathrm{I} / t$ tot, delivered $V \mathrm{~T}$ using the BiPAP in the $\mathrm{T}$ mode fell from $1.23 \mathrm{~L}$ to $0.83 \mathrm{~L}$ when $t \mathrm{I} / t$ tot was lengthened from 0.5 to 0.66 , while other settings remained unchanged.

\section{Effect of varying inspiratory trigger sensitivity}

The O'NYX, Siemens and 335 have adjustable inspiratory triggers, and experiments were performed to test the effect of inspiratory trigger sensitivity on leak compensation. Trigger sensitivity had no effect on delivered $V \mathrm{~T}$ with the 335 (data not shown). However, the Siemens and $\mathrm{O}^{\prime} \mathrm{NYX}$ both increased delivered rates over the set back-up rates at higher inspiratory trigger sensitivity settings (autocycling) (figs. 5 and 6). With the Siemens, rate increased to $30 \cdot \mathrm{min}^{-1}$ and delivered $V \mathrm{~T}$ fell when inspiratory sensitivity was set below $0.6 \mathrm{cmH}_{2} \mathrm{O}$ for a small leak, and $0.8 \mathrm{cmH}_{2} \mathrm{O}$ for a large leak. With the $\mathrm{O}^{\prime} \mathrm{NYX}$ in the ACPV mode, autocycling did not occur in the presence of a small leak. However, with a large leak and more sensitive trigger sensitivity settings ( 0.5 and $\left.1.5 \mathrm{cmH}_{2} \mathrm{O}\right), V$ T dropped dramatically while respiratory rates climbed to $36 \cdot \mathrm{min}^{-1}$, and the ventilator failed to maintain PEEP in the inspiratory tubing (fig. 6).
Autocycling did not occur when the sensitivity was set at $3 \mathrm{cmH}_{2} \mathrm{O}$, even with a large leak, and leak compensation was much improved.

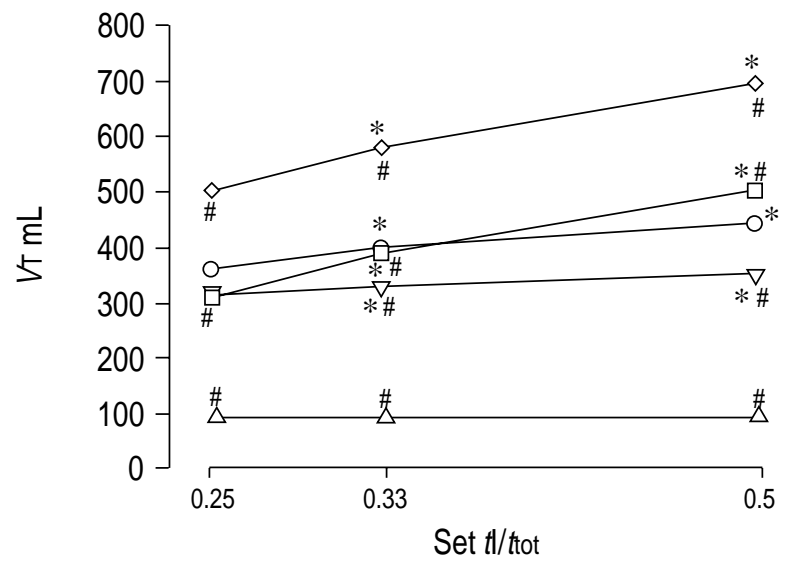

Fig. 4. - Effect of set inspiratory time/total time $(t \mathrm{I} / t$ tot $)$ in the presence of a large leak on delivered tidal volume $\left(V_{\mathrm{T}}\right)$ in four pressure targeted ventilators $(\bigcirc: 335 ; \nabla$ : Bilevel positive airway pressure (BiPAP) S/T; $\square$ : BiPAP T; $\diamond$ : Quantum; $\triangle$ : Siemens pressure control ventilator $(\mathrm{PCV}))$. Inspiratory/expiratory positive airway pressure (IPAP/EPAP) settings were 18 and $5 \mathrm{cmH}_{2} \mathrm{O}$, respectively, and test lung compliance was $0.1 \mathrm{~L} \cdot \mathrm{cmH}_{2} \mathrm{O}$. The \%IPAP control is inoperative with the BiPAP in the S/T mode, but $t \mathrm{I} / t$ tot is plotted according to where the knob was set and actual $t \mathrm{I} / t$ tot is given in the text. The inspiratory and expiratory sensitivity settings on the 335 were 2 and 3 respectively and on the Siemens $1.0 \mathrm{cmH}_{2} \mathrm{O}$. *: $\mathrm{p}<0.01$ compared to value at $t \mathrm{I} / t$ tot $0.25 ; \#: \mathrm{p}<0.01$ compared to 335 . 


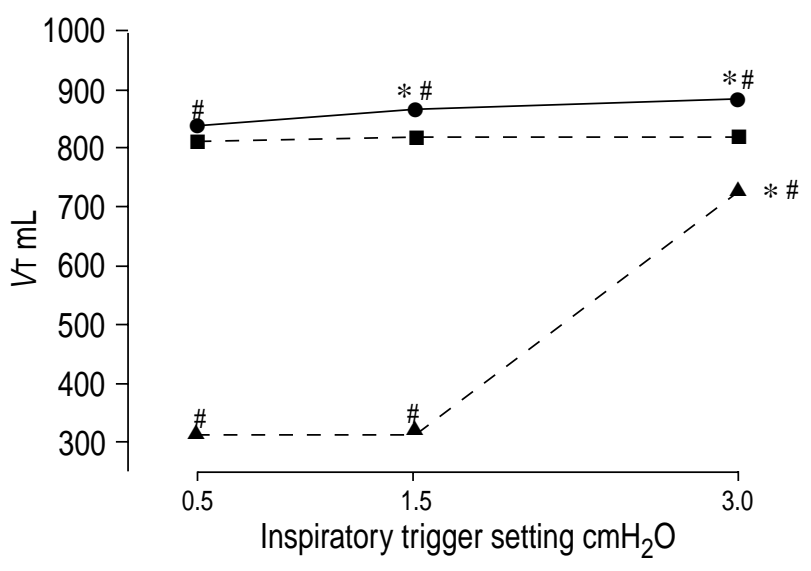

Fig. 5. - Effect of inspiratory trigger settings on delivered tidal volume $\left(V_{\mathrm{T}}\right)$ in the absence and presence of leak in the assist controlled pressure ventilation (ACPV) mode on the $\mathrm{O}^{\prime} \mathrm{NYX}$ ventilator. Inspiratory/expiratory positive airway pressure (IPAP/ EPAP) settings were 18 and $5 \mathrm{cmH}_{2} \mathrm{O}$, respectively, inspiratory time/total breath time $(t \mathrm{t} / t$ tot $)$ was 0.33 , and test lung compliance was $0.1 \mathrm{~L} \cdot \mathrm{cmH}_{2} \mathrm{O}$. At the more sensitive inspiratory trigger settings with a large leak, autocycling occurred and leak compensation was negligible. *: $\mathrm{p}<0.05$ compared with value at 0.5 setting; \#: $\mathrm{p}<0.05$ compared with small leak.

\section{Leak compensation with volume-targeted modes}

As anticipated, delivered $V \mathrm{~T}$ with the volumetargeted modes was much lower during leaks than with pressure-targeted ventilators, because of their inability (PLV) or limited ability $\left(\mathrm{O}^{\prime} \mathrm{NYX}\right.$ and Siemens) to compensate by sustaining or increasing inspiratory flow rates (fig. 2, table 2). Some increase in inspiratory flow rate occurred with some of the volume-targeted modes, particularly with the $\mathrm{O}^{\prime} \mathrm{NYX}$ ACV mode, accounting for its greater leak compensating abilities compared to the PLV (fig. 2). In contrast to the pressure-targeted ventilators, as set $t \mathrm{I} / t$ tot on the PLV 102 was increased from 0.25 to 0.33 to 0.5 , delivered $V \mathrm{~T}$ fell slightly related to proportionate decreases in inspiratory flow rate, regardless of the presence of leak in the system (fig. 7). In addition, introducing a leak into the system reduced delivered $V \mathrm{~T}$ at all $t \mathrm{I} / t$ tot settings more than with the pressure-targeted ventilators (fig. 2b), particularly with the PLV 102. On the other hand, for small leaks, increasing set $V \mathrm{~T}$ from $500 \mathrm{~mL}$ to $2 \mathrm{~L}$ increased delivered $V \mathrm{~T}$ substantially during use of the $\mathrm{O}^{\prime} \mathrm{NYX}$ and Siemens and slightly during use of the PLV (fig. 8). However, none of the volume-targeted modes was able to compensate for large leaks, even at the higher set VTs (fig. 8).

Effect of changes in respiratory system impedance on leak compensation

As would be anticipated during pressure-limited ventilation, increases in respiratory system impedance resulting from either reduced lung compliance or increased airway resistance reduced delivered $V \mathrm{~T}$, as exemplified by the 335 (fig. 9). In response to air leaking, delivered $V \mathrm{~T}$ were further reduced, proportionate to the decreases in $V \mathrm{~T}$ observed in the absence of leak (fig. 9). Responses of the other pressure-limited ventilators was similar, and $t \mathrm{I} / t$ tot of the BiPAP S/T was not altered by changes in resistance or compliance. In contrast, the volume-limited PLV 102 maintained $V \mathrm{~T}$ delivery despite changes in test lung compliance, as would be anticipated (data not shown).
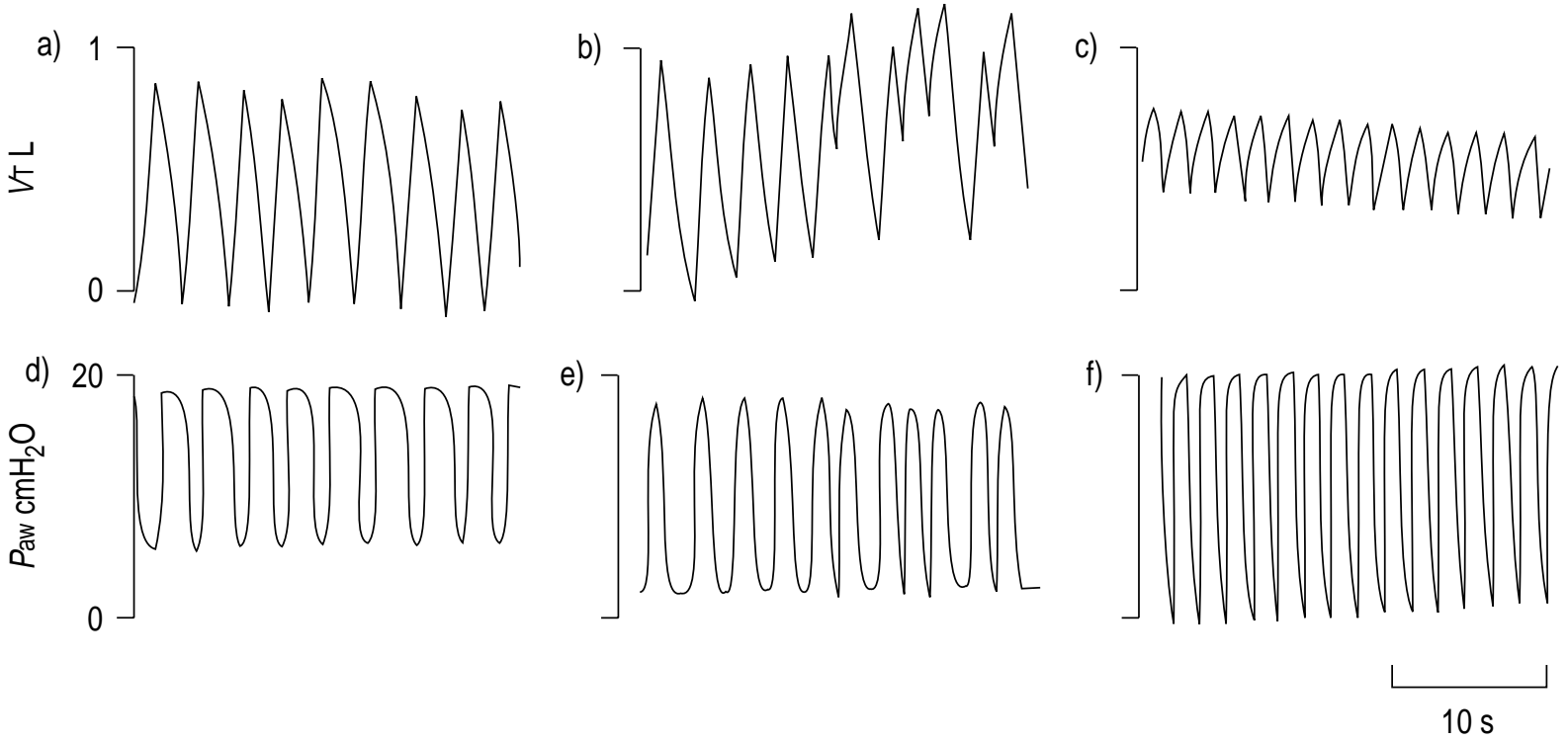

Time

Fig. 6. - Recording of tidal volume $\left(V_{\mathrm{T}}\right)$ and airway pressure $\left(P_{\mathrm{aw}}\right)$ changes during autocycling with the $\mathrm{O}^{\prime} \mathrm{NYX}$ in the assist controlled pressure ventilation (ACPV) mode in the presence of a small leak (b, e) or large leak (c, f), compared with no leak (a, d). During a small leak, autocycling is intermittent, with a moderate reduction in average delivered $V_{\mathrm{T}}$. With a large leak, autocycling is continuous, rate approaches $36 \cdot \mathrm{min}^{-1}$, positive end-expiratory pressure (PEEP) is not sustained, and delivered $V \mathrm{~T}$ is markedly reduced. Inspiratory/ expiratory positive airway pressure (IPAP/EPAP) settings were 18 and $5 \mathrm{cmH}_{2} \mathrm{O}$, respectively, inspiratory time/total breath time ( $t \mathrm{I} / t$ tot) was 0.33 , and test lung compliance was $0.1 \mathrm{~L} \cdot \mathrm{cmH}_{2} \mathrm{O}$. The sensitivity setting was $0.5 \mathrm{cmH}_{2} \mathrm{O}$. 


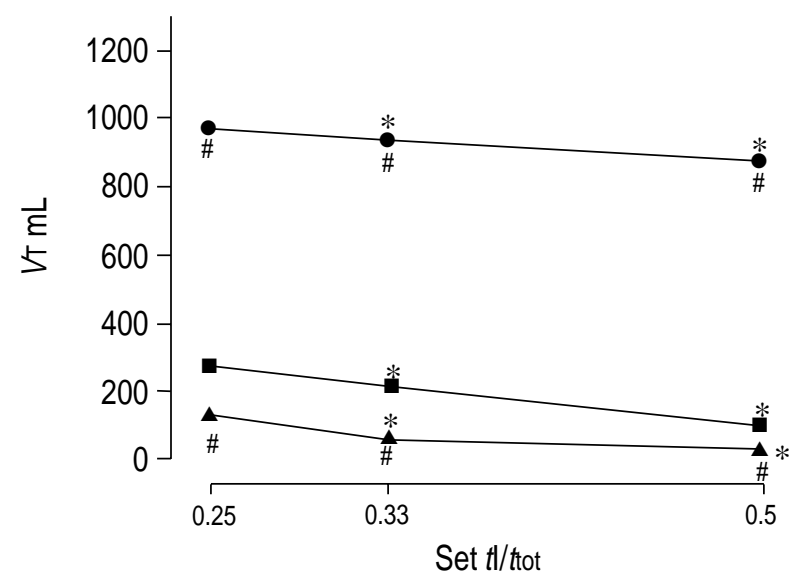

Fig. 7. - Effect of set inspiratory time/total breath time ( $t \mathrm{I} / t$ tot) on delivered tidal volume $\left(V_{\mathrm{T}}\right)$ in the absence and presence of leak with the PLV 102 ventilator. $V_{\mathrm{T}}$ was set at $1,000 \mathrm{~mL}$, and test lung compliance was $0.1 \mathrm{~L} \cdot \mathrm{cmH}_{2} \mathrm{O}^{-1}$. $\mathbf{0}$ : no leak; $\boldsymbol{\square}$ : small leak; $\boldsymbol{\Delta}$ : large leak; $*: \mathrm{p}<0.01$ compared to value at $t \mathrm{I} / t$ tot; \#: $\mathrm{p}<0.01$ compared to 335 .

\section{Discussion}

The presented study demonstrates that the ability to compensate for air leaks varies substantially between ventilators depending on ventilator mode, leak size, inspiratory airflow capabilities, and inspiratory duration as determined by set $t \mathrm{t} / t$ tot or ventilator cycling mechanisms. Although prior investigations have compared the performance characteristics of pressuretargeted portable ventilators [10, 11], few prior published studies have attempted to evaluate the impact of leaks on the efficacy of NPPV. In a recent laboratory study comparing the performance of four positive pressure ventilators, two pressure-targeted ventilators maintained delivered $V \mathrm{~T}$ during leak, whereas the $V \mathrm{~T}$ delivered by two volume-targeted ventilators fell by $>50 \%$ [12]. However, since evaluating the effect of leak was not the primary purpose of the study, the amount of leak was not quantified or varied, and information about peak inspiratory flows during leak was not provided.

Even in the absence of leaks at comparable settings, the five pressure-targeted ventilators in the present study delivered quite different $V$ Ts. The factors accounting for these differences included inaccuracies in delivered versus set inspiratory and expiratory pressures and a longer inspiratory duration when the BiPAP was set in the S/T mode, allowing more time for lung inflation. Because of this property, the BiPAP in the $\mathrm{S} / \mathrm{T}$ mode also exhibited the greatest proportional reduction in delivered $V \mathrm{~T}$ during leaks. This occurred because the sustained high inspiratory flow during leaks prevented termination criteria for inspiration from being reached for up to $3 \mathrm{~s}$, the default setting. At the set respiratory frequency of 20 breaths $\cdot \mathrm{min}^{-1}$, this led to an inversion of the $\mathrm{I}: \mathrm{E}$ ratio to as high as $4: 1$. $V \mathrm{~T}$ fell because of incomplete emptying of the lung due to shortening of the expiratory time.

In the presence of leaks, pressure-targeted modes manifested even larger differences in delivered $V$ T than
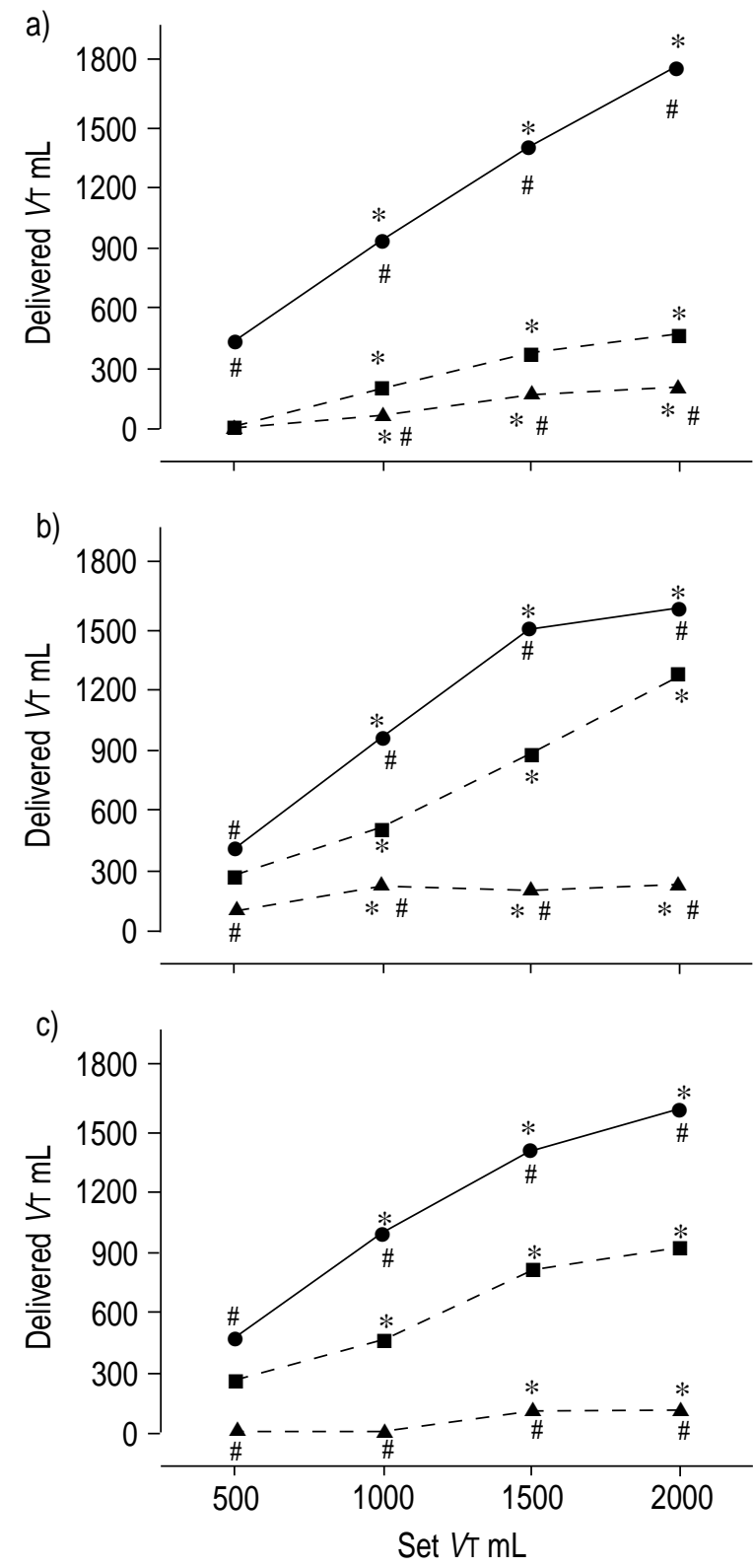

Fig. 8. - Effect of alterations in set tidal volume $\left(V_{\mathrm{T}}\right)$ on delivered $V_{\mathrm{T}}$ in the absence and presence of leak with the PLV 102 ventilator (a), $\mathrm{O}^{\prime} \mathrm{NYX}$ in the assist controlled ventilation (ACV) mode (b) and Siemens 900C in the AC (volume control) mode (c). Inspiratory time/total breath time $(t \mathrm{I} / t$ tot $)$ was set at 0.33 , and test lung compliance was $0.1 \mathrm{~L} \cdot \mathrm{cmH}_{2} \mathrm{O}$. O: no leak; small leak; $\boldsymbol{\Delta}$ : large leak; $*: \mathrm{p}<0.01$ compared to value at $t \mathrm{I} / \mathrm{t}$ tot; $\#: \mathrm{p}<0.01$ compared to 335 .

without leaks. This was related to the ability to increase inspiratory flow and sustain the target inspiratory pressure as well as the duration (inspiratory time). The ventilators that best compensated for leaks (especially large leaks such as the Quantum) were able to increase inspiratory flow rate up to three-fold and lengthened inspiratory duration slightly (table 2). Excessive prolongation of inspiratory time was counterproductive, however, as discussed above. In addition, by demonstrating the reduction in inspiratory flow that occurs with the Siemens ventilator in the face of large leaks 
a)

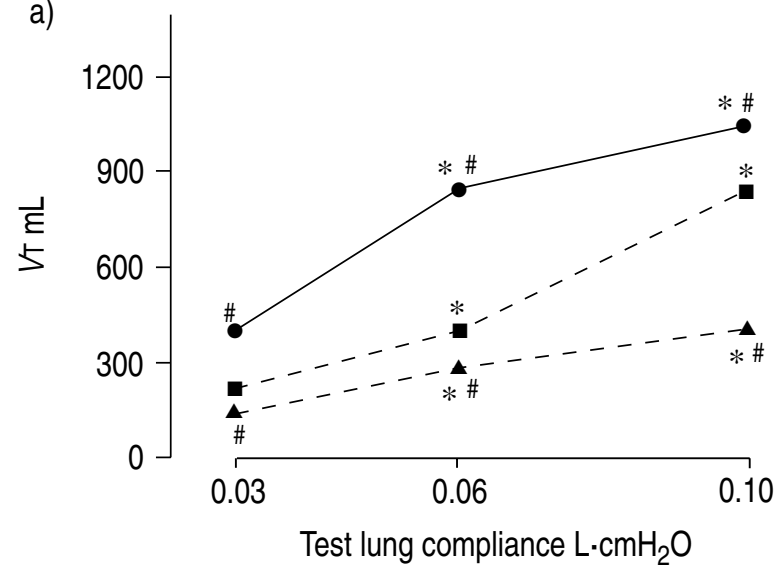

b)

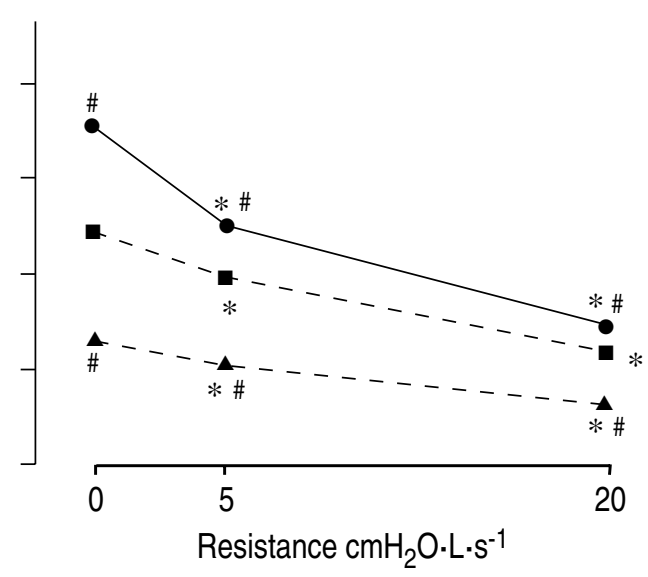

Fig. 9. - Effect of test different lung compliances (a) and inspiratory resistances (b) on delivered tidal volume ( $\left.V_{\mathrm{T}}\right)$ in the absence and presence of leak with the NPB 335 ventilator. Inspiratory/expiratory positive airway pressure (IPAP/EPAP) settings were 18 and $5 \mathrm{cmH}_{2} \mathrm{O}$, respectively, and inspiratory time/total breath time $(t \mathrm{I} / t$ tot $)$ was 0.33 . $\bigcirc$ : no leak; $\mathbf{\square}$ : small leak; $\boldsymbol{\Delta}$ : large leak; *: $\mathrm{p}<0.01$ compared to value at $t \mathrm{I} / t$ tot; $\#: \mathrm{p}<0.01$ compared to 335 .

(fig. 3), the results illustrate the importance of not only attaining a high inspiratory flow rate during leaks, but also sustaining it for the duration of the inspiratory phase.

In contrast to the pressure-targeted modes, ventilators delivering volume-targeted modes compensated less well for leaks because inspiratory flow and duration are either fixed (PLV 102) or increase slightly $\left(\mathrm{O}^{\prime} \mathrm{NYX}\right.$ and Siemens). Accordingly, significant drops in delivered $V \mathrm{~T}$ (at least 50\%) during small leaks and more than $80 \%$ during large leaks were observed. In addition, prolonging $t \mathrm{I} / t$ tot from 0.25 to 0.5 did not increase delivered $V \mathrm{~T}$ as it did with pressure-targeted modes. In fact, delivered $V \mathrm{~T}$ fell slightly, presumably because of the greater inspiratory duration and resulting longer leak time. In the presence of a small leak, compensation was achieved by increasing set $V \mathrm{~T}$ to $2 \mathrm{~L}$ as delivered $V \mathrm{~T}$ was raised to 500,900 and $1200 \mathrm{~mL}$ for the PLV 102, Siemens and $\mathrm{O}^{\prime} \mathrm{NYX}$ ventilators, respectively. Nevertheless, this strategy for leak compensation is less effective than using pressure-targeted ventilators. Thus, volumetargeted ventilators would not be the first choice for NPPV in patients with substantial air leaking.

Some of the pressure-targeted ventilators permit setting of the I: E ratio (the BiPAP T mode, 335, and Quantum). Prolonging the inspiratory duration by increasing the set $t \mathrm{I} / t$ tot from 0.25 to 0.33 or 0.5 improved leak compensation. However, this compensatory effect depends on the rate of lung filling and emptying and the absolute inspiratory duration. For instance, increasing the $t \mathrm{I} / t$ tot beyond 0.25 at a rate of 10 would probably have less effect than at a rate of 20 because the inspiratory duration at the lower rate would allow complete lung filling [13]. On the other hand, prolonging the inspiratory time to the point of inverting the $\mathrm{I}$ : E ratio is counter-productive at a rate of 20 , as exemplified by the drop in delivered $V \mathrm{~T}$ when the $t \mathrm{I} / t$ tot was increased from 0.5 to 0.66 on the BiPAP in the $\mathrm{T}$ mode. Other potential clinical consequences of inversion of the $\mathrm{I}$ : $\mathrm{E}$ ratio include the need for patients to activate their expiratory muscles of respiration in order to cycle into EPAP, air trapping due to inadequate expiratory time, and patient-ventilator asynchrony that contributes to patient discomfort and NPPV intolerance. Thus, the capability of limiting $t \mathrm{I} / t$ tot to no more than $50 \%$ of the respiratory cycle time can help to prevent excessive shortening of expiratory time. In patients with severe COPD, a shorter $t \mathrm{I} / t$ tot may be desirable to enhance patient-ventilator synchrony. Previous studies have shown that relatively high inspiratory flow rates (and hence short inspiratory times) reduce work of breathing during pressure support breathing in these patients [14].

The present results also illustrate the potential adverse consequences of sensitive flow triggers during leaking. At the more sensitive inspiratory trigger settings on the $\mathrm{O}^{\prime} \mathrm{NYX}$ and Siemens ventilators, air leaking caused autocycling and marked reductions in delivered $V \mathrm{~T}$ due to the shortening of inspiratory and expiratory times. Flow-triggered ventilators are susceptible to autocycling in the presence of a leak because the leak flow may be interpreted by the ventilator as the onset of inspiration. In a study evaluating three paediatric flow-triggered intensive care ventilators [15], the relative rate of autocycling by the three ventilators was determined by the sensitivity setting, and all of the ventilators autocycled less frequently at decreased sensitivity settings. The presented findings are consistent with these, with rapid respiratory rates occurring during both small and large leaks. These results indicate that monitoring should be performed during use of ventilators with adjustable inspiratory triggers, and trigger sensitivity should be set to avoid autocycling. It should also be noted that certain ventilators are resistant to autocycling by design. For instance, the BiPAP S/T that did not autocycle in our study, has a higher threshold for inspiratory triggering early compared to later during expiration [16].

As anticipated, increases in respiratory impedance caused by increases in test lung elastance or resistance resulted in reductions in $V \mathrm{~T}$ delivered by the pressurelimited modes, but had little effect on $V \mathrm{~T}$ delivered by the volume-targeted PLV 102. Thus, in the setting of increased airway resistance or respiratory system 
elastance, there are several choices available to the clinician. If leaks are minimal, volume-targeted ventilation can be used to assure delivered $V \mathrm{~T}$ despite the increased impedance. However, because leaks are so common during NPPV, pressure-targeted ventilators may be preferred to compensate for the leaks as long as ventilator pressures or inspiratory times are adjusted to optimize delivered $V$ T. However, the effectiveness of these latter compensatory actions is limited by the patient's tolerance of increased pressures during NPPV, and the increased pressures could exacerbate the leak [17].

A number of limitations should be borne in mind when interpreting the present results. First, a test lung was used in order to compare the ventilators under identical mechanical conditions, but the observations have not been validated in patients. Second, responses were not tested at a range of back-up rates and pressures and only two leak sizes were used. These choices were made in order to simplify data presentation, and to represent the range of settings commonly encountered clinically [10]. The two leaks were selected to range below and above those measured in a previous clinical study [3], and ideal settings were used for NPPV based on recommendations in the literature [8, 9]. Third, the effects of leak on ventilator triggering or cycling during spontaneous breathing were not tested, so the observations are most relevant to situations where controlled breathing predominates, such as in neuromuscular patients during sleep [3]. Fourth, with advances in technology, newer versions of some of the ventilators tested might perform differently. Finally, one representative ventilator of each type was tested and that individual ventilators may differ was allowed for. The study was designed mainly to illustrate certain response patterns of ventilator modes in the presence of air leaking, and should not be construed as an efficacy comparison between specific ventilators in compensating for leaks. The present results should alert practitioners to the need for calibration and close monitoring of ventilators used for NPPV, and for careful selection of ventilator settings.

In conclusion, pressure-targeted modes maintain delivered $V \mathrm{~T}$ in the presence of leaks better than volume-targeted modes. Hence, pressure-targeted ventilators are preferred over volume-targeted ventilators to provide more effective NPPV in patients with substantial air leaking. To best compensate for air leaks, pressure-targeted ventilators should have high and sustained maximal inspiratory flow capabilities $\left(>3 \mathrm{~L} \cdot \mathrm{s}^{-1}\right)$, adjustable $\mathrm{I}: \mathrm{E}$ ratios or other mechanisms to limit inspiratory duration so that inversion of the I:E ratio is avoided, and adjustable trigger sensitivities or algorithms to prevent autocycling.

Acknowledgements. The authors thank Respironics and Mallinckrodt Nellcor Puritan Bennett for providing the ventilators. The authors would also like to thank MNPB instruments for providing the test lung.

\section{References}

1. Meyer TJ, Hill NS. Noninvasive positive pressure ventilation to treat respiratory failure. Ann Intern Med 1994; 120: $760-770$.

2. Mehta S, Hill NS. Noninvasive ventilation in acute respiratory failure. Resp Care Clinics N America 1996; 2: $267-292$.

3. Meyer TJ, Pressman MR, Benditt J, et al. Air leaking through the mouth during nocturnal nasal ventilation: effect on sleep quality. Sleep 1997; 20: 561-569.

4. Hendrix TR. The motility of the alimentary canal. In Medical Physiology, 14th Edition. Mountcastle VB, ed. St. Louis, Mosby, 1980; pp. 1320-1347.

5. Bach JR, Dominique R, Leger P, Langevin B. Sleep fragmentation in kyphoscoliotic individuals with alveolar hypoventilation treated by NPPV. Chest 1995; 107: $1552-1558$.

6. Hill NS. Complications of noninvasive positive pressure ventilation. Respir Care 1997; 42: 432-442.

7. Hill NS, Mehta S, Carlisle CC, McCool FD. Evaluation of the Puritan-Bennett 335 portable pressure support ventilator: comparison with the Respironics BiPAP S/T. Respir Care 1996; 41: $885-$ 894.

8. Parreira VF, Jounieaux V, Aubert G, Dury M, Delguste P, Rodenstein DO. Nasal two-level positive pressure ventilation in normal subjects. Am J Respir Crit Care Med 1996; 153: 1616-1623.

9. Parreira VF, Jounieaux V, Delguste P, Aubert G, Dury M, Rodenstein DO. Determinants of effective ventilation during nasal intermittent positive pressure ventilation. Eur Respir J 1997; 10: 1975-1982.

10. Kacmarek RM. Characteristics of pressure-targeted ventilators used for noninvasive positive pressure ventilation. Respir Care 1997; 42: 380-388.

11. Bunburaphong $T$, Imaka $H$, Nishimura $M$, Hess D, Kacmarek RM. Performance characteristics of bilevel pressure ventilators. A lung model study. Chest 1997; 11: $1050-1060$.

12. Smith IE, Schneerson JM. A laboratory comparison of four positive pressure ventilators used in the home. Eur Respir J 1996; 9: 2410-2415.

13. Strumpf DA, Carlisle CC, Millman RP, Smith KW, Hill NS. An evaluation of the Respironics BiPAP bilevel CPAP device for delivery of assisted ventilation. Respir Care 1990; 35: 415-422.

14. Bonmarchand $\mathrm{G}$, Chevron $\mathrm{V}$, Chopin $\mathrm{C}$, et al. Increased initial flow rate reduces inspiratory work of breathing during pressure support ventilation in patients with exacerbation of chronic obstructive pulmonary disease. Intensive Care Med 1996; 22: $1147-1154$.

15. Bernstein G, Knodel E, Heldt GP. Airway leak size in neonates and autocycling of three flow-triggered ventilators. Crit Care Med 1995; 23: 1739-1744.

16. Technical Manual, BiPAP S/T, Respironics, Murrysville, PA, 1994.

17. Jounieaux V, Aubert G, Dury M, Delguste P, Rodenstein DO. Effects of nasal positive-pressure hyperventilation on the glottis in normal sleeping subjects. J Appl Physiol 1995; 79: 186-193. 